\title{
HCI Tactics for Politics from Below: Meeting the Challenges of Smart Cities
}

\author{
Cedric Deslandes Whitney \\ Feminist Labor Lab, University of \\ California, Berkeley \\ Berkeley, California, USA \\ cedricwhitney@berkeley.edu \\ Simrandeep Singh \\ Feminist Labor Lab, University of \\ California, San Diego \\ La Jolla, California, USA \\ simsinght@gmail.com
}

\author{
Teresa Naval \\ Feminist Labor Lab, University of \\ California, San Diego \\ La Jolla, California, USA \\ tnaval@ucsd.edu \\ Steven R. Rick \\ Design Lab, University of California, \\ San Diego \\ La Jolla, California, USA \\ srick@eng.ucsd.edu
}

\author{
Elizabeth Quepons \\ Feminist Labor Lab, University of \\ California, San Diego \\ La Jolla, California, USA \\ equepons245@gmail.com \\ Lilly Irani \\ Feminist Labor Lab \& Design Lab, \\ University of California, San Diego \\ La Jolla, California, USA \\ lirani@ucsd.edu
}

\begin{abstract}
As crucial public functions are transferred to computer systems, emerging technologies have public implications that are often shaped beyond public influence and oversight. "Smart city" and "modernization" projects are just some examples of such transformations. This paper focuses on struggles over the acquisition, control, and maintenance of these public, digital infrastructures. We focus on the forms of $\mathrm{HCI}$ knowledge and practice that proved useful to a coalition of community organizations claiming rights of input into and political oversight over surveillance technology. Their claims were a response to their exclusion from decision-making about smart city implementation in San Diego. We offer tactics "from below" as a way to attune HCI to the needs and practices of those excluded from power over widespread technology infrastructures. Ultimately, we argue that HCI cultivates a variety of capacities beyond design and redesign that can strengthen struggles to shape real-world technologies from below.
\end{abstract}

\section{CCS CONCEPTS}

- Human-centered computing $\rightarrow$ Empirical studies in $\mathrm{HCI}$; Participatory design; $\bullet$ Social and professional topics $\rightarrow$ Surveillance.

\section{KEYWORDS}

critical/activism/ethics, maker culture, city, participatory design

\section{ACM Reference Format:}

Cedric Deslandes Whitney, Teresa Naval, Elizabeth Quepons, Simrandeep Singh, Steven R. Rick, and Lilly Irani. 2021. HCI Tactics for Politics from Below: Meeting the Challenges of Smart Cities. In CHI Conference on Human Factors in Computing Systems (CHI '21), May 8-13, 2021, Yokohama, Japan. ACM, New York, NY, USA, 15 pages. https://doi.org/10.1145/3411764.3445314

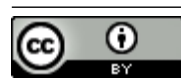

This work is licensed under a Creative Commons Attribution International 4.0 License.

CHI '21, May 8-13, 2021, Yokohama, Japan

(c) 2021 Copyright held by the owner/author(s).

ACM ISBN 978-1-4503-8096-6/21/05.

https://doi.org/10.1145/3411764.3445314

\section{INTRODUCTION}

Public agencies entrusted with many functions, from voting to service delivery, are routing these practices through digital technologies. Those technologies are sometimes built within the public sector, but more often subcontracted to private sector companies that offer off-the-shelf or configurable software and cloud services $[8,71,83]$. As crucial responsibilities are increasingly transferred to computer systems, however, systems of public consequence are "black boxed" [94] by closed-source code, security-by-obscurity policies, outsourcing to private companies, or simply closed door agency processes that exclude public participation and oversight [22]. These projects become acts of governance through technological design, but government agencies can claim them to be technical decisions or decisions made in the interest of an imagined generic public [89]. While computational mediation of statecraft is not new [2], the proliferation and privatization of these systems has expanded in recent decades $[43,54,71,111]$. In this shift, participation in design extends to questions of how systems are acquired and configured [8], whose priorities are privileged, and what harms to communities are normalized in the process $[15,43,111]$.

The "smart city" is just one iteration of visions by which this digitalization of governance unfolds. Cities have historically been a site of speculation, both social and, in capitalist places, financial [30]. In recent decades, projects called "modernization," "innovation districts" and "smart cities" have made technology interesting to real estate developers, elected officials, and others interested in transforming urban space [115]. Central to such visions are the rollout of information and communication technologies that capture and accumulate "volumes of data generated about city spaces from city spaces" [75]. Take Hudson Yards in Manhattan as one example: a sprawling development that includes residences, hotels, shops, and art installations. Developers envisioned it as a site of experimentation for urban data science as a "quantified community." In doing so, they used the vision of informational smartness to displace the idea of a city where all have a right to live and participate. Hudson Yards became one of the cities all time costliest developments, engendering the displacement of low income and queer communities in New York [73, 88]. Such displacement is not new; centuries old projects have attempted to control the mobility 
of bodies and the purity of spaces from the presence of those cast as Other [19, 113]. However, the accumulation of data from city spaces, social media, cell phone locations, and other sources multiply experiments not only in living, but also in surveillance [98]. Smart city technologies, often sold to the public with the promise of convenience (easier parking, traffic reduction, etc.) and energy savings, come with less public pitches that also bring intensified law enforcement and regulatory technologies [98].

In San Diego, the City quietly launched a project that placed over 3,000 streetlights equipped with cameras, microphones, object detection algorithms, and app-upgradeable functionality overseeing residents and visitors. The San Diego City Council voted on the project only as a "smart light" energy saving program without grappling with its surveillance implications. City champions - the Mayor and some of his staff - revealed more dimensions of the program as they engaged San Diego's tech entrepreneurs and "innovation" enthusiasts in the 2016 launch of the program. Many other communities only found out about the program in 2019 when the city held community forums to expand the program. By late 2019, thirty community groups formed a coalition and engaged in direct action to learn more about the program, broaden community knowledge of surveillance technology, and to demand community input and elected official oversight of this and future surveillance-related projects in the city. This paper documents technological practices of residents organizing to demand a role in the design and oversight of city computational technologies, despite their exclusion.

We build on prior empirical work on smart cities and civic innovation showing how citizens are either represented by professional and bureaucratic elites, or are entirely absent from key decision making spaces save the occasional outreach effort [101]. Smart city projects typically frame the citizen as a service user [71], an entrepreneurial innovator [64,101, 114], or a civic volunteer [55]. On the other hand, smart city champions have neglected, scholars find, the implications for citizenship rights, especially of the criminalized and vulnerable (e.g. family members of undocumented people, low wage workers, etc.). As a concept, citizenship emphasizes people not as "users" or "humans" but as people who claim rights and bear responsibilities in relation to the state $[64,76,96]$. Where the literature identifies a neglect, this paper makes present those removed from key decision-making spaces over smart cities. Contemporary HCI research on civic participation has grappled with similar questions, developing design practices such as participatory design, speculative design, and critical design to help solidify the role of $\mathrm{HCI}$ in democratic processes [34, 41, 108]. Our contribution is to look beyond design towards direct action $[7,70]$ and towards refusals [21], policy [68], and accountability, as a means to empower people to shape these technologies. This paper, then, offers an example of an ongoing struggle to articulate technological citizenship from below and offers HCI ways to expand its repertoires of practice to contribute to such efforts.

We utilize the language of "above" and "below" to emphasize and articulate the tensions between the wants, needs, and knowledge of unequally empowered stakeholders. Techniques from above include visions of the future as described by technocrats, government actors, or company management - actors who often work in coordination. In contrast, techniques from below highlight the workarounds and counter-practices of those subordinate or subjected to governance from above. Such techniques from below are informed and refined by everyday interactions people have with these sociotechnical systems and their histories. While above and below are simplifications of more complex power relationships among people, organizations, and knowledge [44, 47], in this paper below marks our position, as community members in coalition, to those above in City Hall and corporate headquarters. Those above have the power to deploy, shut down, and reconfigure smart city technologies, and otherwise control how they are produced and reproduced. We recognize HCI scholars and researchers are often figuratively above, working in companies or research institutions that design and install computation in others' lives [58]. However, many of us are often also below in the sense that we are unable to assert our vision for good technology over decision makers above us in companies and in the state. We advocate for an HCI that works - and chooses to work - from below to stand with communities against potentially harmful visions of the future.

In reflecting on our work as HCI researchers in the coalition, we argue HCI cultivates a variety of capacities beyond design, from interpreting technological possibilities of contracts and data pulled through application programming interfaces (APIs) to contesting dominant speculative narratives through storytelling and expertise claims. These capacities can meaningfully contribute to the struggle to shape real-world technology from below. These capacities, we find, were unique to our background as technologists in the coalition and proved useful in the struggle over governance, but are not recognized as HCI ways of knowing [92].

This paper begins by introducing the literature on community participation and design, as well as the relationship between infrastructure and politics within and beyond the fields of design and HCI. We focus on counter-practices to build power over technology when power has not been given. In these settings, the struggles over technology are not focused on new design or design fixes, but instead on struggles over interpretation, acquisition, configuration, maintenance, and regulation. We illustrate this through the case of a community coalition formed in the Alinskyan model [3] in response to the implementation of smart city infrastructure in San Diego.

\section{RELATED WORK}

In attempting to ensure voices from below are heard and designed for, designers have turned towards projects of inclusion. These attempts have ranged in scope, from participatory design, where designers focus on "fieldwork of the future" [91] to understand direct users needs and ideas around future technologies, to value sensitive design, which expands the concepts of participatory design to those who are described by Friedman et al. as "indirect stakeholders" [51] affected by the technology even when they are not explicitly the users of the technology. In utilizing stakeholder participation, including through methods such as hackathons "for social good" [55, 61], these design methods seek to better understand the "ongoing entanglements" [112] that only those stakeholders are truly situated in.

Participatory design scholars have identified two contemporary challenges of special relevance to our case: 1) Software is mostly 
bought off the shelf, making acquisition rather than design a fulcrum of power [8]; and 2) Institutions acquire, configure, and maintain software, and thus participatory design must grapple with institutional processes [13, 34, 63]. Otherwise, participatory design can be appropriated for exclusionary purposes, subject to "the production of a creative economy" [71]. Ghoshal et al's [52] call for "a grassroots culture of technology practice rooted in analyses of systemic exclusion" represents one form of push back against the commodification of participation. Recent work successfully uses co-design tactics $[67,99]$ to create alternatives for grassroots communities [42, 59, 61, 97, 110]. Lyle et al [81] demonstrated strategies and tactics for how this can be done while explicitly embracing an activist agenda, in the Europe-based Commonfare project where design researchers created new infrastructures for autonomous social collaboration, drawing directly from grassroots initiatives to strengthen public formation.

Our work builds on these participatory design approaches to redistributing power in the making of technology. Teli et al [108] detail the relationships between design researchers, institutions, and grassroots communities in their attempts to do this in their exploration of institutioning and commoning. These include situated reflexive practices that call on designers to "to acknowledge responsibilities, the possibility of being assimilated, and the need for long-time commitment." We build from this call. We also follow a call for participatory design to re-engage with institutions [78] and political action [13]. We offer tactics for demanding participation from below that build on capacities of HCI practitioners and contribute to community organizing and political claim making. Crucially, previous work argues for highlighting points of convergence between institutional and community actors, but our work emphasizes the importance of highlighting divergent needs and difference as well. While participatory design often focuses on preferred futures [72], we emphasize the imagination [112] of and organizing around dispreferred futures through means including but also beyond - design.

Politics and, by extension, "the political" here do not simply mean the techniques and application of governance, or participation and engagement in some form of civil society. We build on understandings of the political as a struggle to interject new positions or differences into the public sphere, competing with attempts to close down participation to delimited processes or terms of legibility [93]. We also build on theorists who formulate politics as a struggle for power to define social meanings and control or restructure key institutions [53]. Within HCI, adversarial design, as coined by Carl DiSalvo, advocates for design as a method of highlighting the political [33]. It views design through the lens of agonism, facilitating the constant reframing and reflection of political issues through the act of creation. This reframing can be utilized to forefront political claim-making in the interests of citizenship from below.

In moving beyond a focus on design to a wider-range of politically engaged practices, we offer one possible response to Paul Dourish's [36] argument that usability has become HCI's legitimacy trap: the field's claim to worth and a category that limits its efficacy on questions of how computation can support "dignity and human flourishing." We join calls for a social justice-oriented HCI that can tackle "system or 'wicked' problems [that] present challenges for design practice due to their scope, scale, complexity, and political nature" [35] while actively working against the reproduction of existing inequalities [29]. This requires refusing the promise of a "technological fix" $[4,102]$ in favor of analyzing harms and engaging in formations of solidarity that subvert power dynamics in knowledge and technology production [15]. The ends of such work might be better technology, but only because the work creates strong social relationships, redistributes resources, and builds counter-structures [7, 66]. The process, then, is as important, or arguably more important than, the outcome. In focusing on what Keshavarz and Maze specify as the "'political frontier', in which other, situated forms of knowledge are embodied in socialand change-oriented practices" [69], this paper seeks to detail how HCI knowledge integrates with other communities' knowledge in fighting for dignity in relation to technology when design is neither possible, nor desirable [12], nor enough [36].

\section{OUR APPROACH}

This paper offers a reflection on our team's work in San Diego supporting a coalition of community organizations working to understand and influence smart streetlight infrastructures through policy and direct action. This reflection on HCI practice occurred within relations of what Suchman describes as located accountability [107]. Two authors kept fieldnotes on their work with the coalition, including event descriptions, meeting notes, screenshots of public digital media interactions, and notes on conversations. The last author is a coalition steering committee member, present at most private and public coalition meetings, note taking throughout. The second author also took field notes on our HCI activities. We extensively researched historical records related to the streetlight program by analyzing and archiving news clips, City Council meetings, trade publications, and public records. Uncited facts are drawn from our notes. Additionally, we engaged in a speculative design practice that we termed a 'slightly dystopian hackathon', building demos on publicly accessible smart streetlight APIs in an attempt to help the coalition. The hackathon was generative for our group but the coalition ultimately found use not in the demos but in the insights generated through the work [72]. They asked us to document those insights as a public policy report on technological failings - and the failed promises - of the smart infrastructure. We elaborate and reflect on these activities below.

Our reflection and subsequent tactics from below are heavily influenced by Alinskyan organizing. Saul Alinsky was mainly concerned with organizing disenfranchised people to exercise political power for change. He detailed that "change comes from power, and power comes from organization. In order to act, people must get together" [3, p. 120]. He urged agitation to get people to "effectively conflict with the prevailing patterns and change them" [3, p. 123]. Coalitions are organizations that bring together different community groups to engage in concerted, coordinated action towards shared goals. Coalition allows for prevailing differences among groups to coexist without attempting to subsume them under one master theory or political identity, and it allows for those differentiated groups to engage in a complex struggle with one another towards a goal [48]. The 'incommensurate' nature of agonism and coalition $[17,38,77]$ at first may seem to be a contradiction, but 
Alinskyan organizing is predicated around directing that agonism outward against targeted decision makers. The San Diego TRUST Coalition drew from these practices, bringing together tech workers the city tries to attract through gentrification with the Black communities policed in the name of the same gentrification; Muslims and Asian Americans who are stereotyped in very different ways also came together. As Black feminist Bernice Johnson Reagon put it in 1981, "The only reason you would try to team up with someone who could possibly kill you, is because that's the only way you can figure out how to stay alive" [103].

Organizing in the Alinskyan model is focused on helping people see problems as issues they can collectively tackle and then utilizing relationships to tackle them, and HCI researchers and research can assist in this. By learning and building relationships before and throughout the design process, we can enable communities to identify "issues" that matter most to them and then be able to work with them. By being accountable to relationships with the coalition, we learned how we could support their needs, not just through design but through our contributions to strategy, narrative building, and epistemic legitimacy. Our tactics from below draw on who we are and what we know from HCI to experiment with new ways to contribute to such power building. These experiments, explained below, follow what Adrienne Maree Brown calls "emergent strategy" for starting where we are and finding new ways to build and sustain counterpower movements [18]. The following section details where we started.

\section{HOW STREETLIGHTS BECAME POLITICIZED}

\subsection{The view from above}

Before discussing how smart streetlights were embedded in the city infrastructure, we must first introduce the particularities of San Diego - such as its status as a border city, its relationship to the U.S. Navy and the flow of military officers across the Pacific Ocean, the density of biotechnology corporations, its high cost of living and its wealth disparities. According to a UK-based privacy research group, San Diego is one of the top five most-surveilled big cities in the US [106]. San Diego also has a large presence of Immigration and Customs Enforcement (ICE) officers - officers that, in their search for undocumented people, often stop and detain people of color - and that presence is one that has been confirmed to use and access facial recognition technology [82]. It is in San Diego this narrative begins, and while attempts to build smart cities are happening elsewhere, focusing on San Diego as the site of struggle emphasizes the far-reaching and deep effects of public infrastructure like streetlights - and how, as we show in this paper, these streetlights have become technologies under which all those who live, work, or pass by have a stake in.

In 2016, the Mayor's staff and the Environmental Services Department proposed a $\$ 30$ million smart streetlight initiative to the City Council to bring down energy costs. General Electric (GE) sought to roll out their new intelligent sensors, known as CityIQ nodes. The corporation offered to finance the installation of the nodes via a \$30 million loan that the City of San Diego would supposedly be able to pay back through energy savings from the nodes over 13 years. This meant that the project that GE would eventually describe as the largest "Internet of Things" rollout in the world could be written off as practically free [84]. These nodes have video and audio capabilities, as well as computing hardware and environmental sensors. This functionally turned each of the $4000+$ streetlights with CityIQ nodes into surveillance devices, each capable of taking, storing and analyzing 1080p videos and pictures, as well as other sensor data including temperature, pressure, humidity, vibration, and magnetic fields. The City made a public API to provide detailed metadata drawn from this surveillance, such as where pedestrians are, how fast they are moving, and in what direction, in real time from each node. In 2016, City Council voted to approve the rollout of the smart streetlights with no public discussion of this data collection and its associated surveillance capabilities.

This was also technology of gentrification. The city had previously piloted the technology in East Village, an area of downtown San Diego targeted for transformation from retail and social services into a gentrified technology industry hub. Technology hubs too often raise rents and property values and create jobs accessible only to highly trained professionals, displacing or even eroding job quality for historically and systematically oppressed residents. Beyond the buildings, land, and zoning shaped to enable these hubs, technology hubs also require new social structures and financial mechanisms to be directed towards technology production, and away from existing industries and workers. These new social structures are reinforced by "social, racial, and gender exclusivity" [115], with academic and industry talent pipelines further reinforced by investment capital.

The City opened CityIQ data to the public as part of a project of gentrifying economic development. Soon after Council approval, the Mayor of San Diego launched the smart streetlights, standing side-by-side with GE Current's CEO, to San Diego's tech entrepreneurs and enthusiasts. He explained the promise of CityIQ APIs were an engine for generating entrepreneurship in San Diego. "We're making San Diego a sandbox for technology that will be increasingly used by cities throughout the world," the mayor explained. "San Diego residents and innovators get to have the largest opportunity to show what this technology can really do" [16]. The launch was followed by CityIQ civic hackathons, panels and promotions at technology conferences, and open data activist meetups. The City installed a data generating infrastructure to support one class of city residents - those privileged with the time and educational investment to build apps unpaid. However, those under the streetlights on their way to jobs, school, or on the streets they called home for the most part had no idea they were becoming data to stimulate entrepreneurial innovation.

The language in the City's communications around open data and the CityIQ API was mostly focused on value generation, rather than civic participation and due process with impacted communities. The evolution of the City's Open Data platform proposal illustrates this focus. The original proposal, dating to 2014 [24], mentioned participatory governance, transparency, and economic development. It was oriented around (and specifically mentioned) promoting civic engagement, service delivery, public communication, and economic development, with the tagline "efficient solutions for government" [25]. This changed drastically as it progressed, with the yearly report in 2017 instead being situated around data as an asset: "fulfilling the Open Data Policy is just part of a 
larger mission of helping people inside and outside of the City get and use data. "Community involvement in this policy, echoing the rollout of the smart city platform, occurred almost solely in panels at conferences largely attended by technologists and the industry, mostly at national or international events held outside San Diego. Such involvement highlights the gap between the promise of smart city infrastructure as a platform for all the material conditions and networks that facilitate and benefit from the collection of data.

\subsection{The response from below}

The city finally held community forums around the technology in June 2019 as they sought to expand the program into additional areas of the city. This is how the final author became involved; Khalid Alexander of Pillars of the Community (PoTC) reached out to a member of San Diego Tech Workers Coalition (TWC). PoTC is a group that works against the criminalization of communities in majority black and brown Southeast San Diego. The last author had heard of the data-gathering streetlights through her ties to UCSD's Design Lab but could see no outlet for her concerns until Alexander reached out. Alexander knew the histories of policing and physical surveillance in San Diego, but wanted people with knowledge of technology to attend an upcoming community forum and ask challenging questions. After attending one sparsely attended community forum, Alexander reached out to people in different community organizations, encouraging them to attend.

At the next forum, approximately sixty people came together to challenge the presentation of the streetlights as a politically neutral addition. This audience came from a wide range of perspectives and areas of expertise, and the community forum was held in a historically Latinx neighborhood's library. The City staff consisted of a spokesperson from Sustainability and a police officer who talked most of the time. The Sustainability staffer briefly explained the hope was that San Diegans could build apps on the data, including apps to find parking and analyze mobility patterns. The police officer explained that the recorded video from the cameras was only retained for five days, after which it would be deleted - unless SDPD downloaded the data for their own purposes. The officer assured the audience the cameras could not view private property, they did not have facial recognition or automated license plate reading, and they did not have audio. Rakesh, a telecom hardware engineer with TWC, asked whether those were hardware or software limitations. "Software limited," an engineer with the city stood up to answer. Another community member raised her hand: "You can still see how many times someone walks into a mosque - their worship patterns." The officer responded, "we only watch it after a violent crime," a claim reporters would later show to be false through public records requests [85, 87]. Another community member raised their hand, "have you set aside funding to better communities with the data?" "I don't follow your question," the city staffer from Sustainability responded. An older man stood up and explained how police spend hours on Facebook building cases against Black youth, looking for evidence to accuse them of gang membership: "what would prevent you," he asked, "from doing that with 'documented gang members'?” His query referred to a much critiqued program that allows police to "document" people as gang members based on checklists they design; those documented are subject to "gang enhancements" that add years to punishments for minor crimes and until recently had no way of even knowing or contesting their categorization as "gang member" by police (see [90]). PoTC, in particular, had vigorously contested gang documentation surveillance and harassment [39]. Ramla Sahid, director of refugee advocacy group Partnership for the Advancement of New Americans (PANA), asked whether the cameras could provide data to Joint Terrorism Task Forces (JTTF) set up by the US Department of Homeland Security to surveil Muslims, and particularly East African, Middle Eastern, and South Asian communities. "Do we have offices that work with JTTF?" the police officer responded, "Yes we do." The meeting went on for two hours; by the end, both Alexander and Sahid publicly called for community oversight of the technology and control of the data by someone other than the police. So many different experiences and forms of expertise generated questions and concerns about what this newly politicized infrastructure could mean. Outside the library, people pouring out of the forum greeted those they knew, reflected on what had happened, or in some cases met for the first time and made plans to meet again.

What became abundantly clear at the meeting was that the police had become the major users of the smart streetlight nodes. (Months later, reporters established that the nodes had become exclusively a tool for police despite wider civic tech aspirations [86].) As evidenced by community members already facing police surveillance and targeting, the CityIQ nodes intensified what urban historian Mike Davis has called an "ecology of fear" [30]. If infrastructures enable the distribution of possibilities and of life [6], the CityIQ system promised technological creativity and entrepreneurial endeavor for one strata of the city and the threat of kafkaesque policing for another.

In the weeks following the forum, a coalition of over 25 local community groups united in a coalition. At first it took "antisurveillance coalition" as a shorthand title, before settling upon TRUST San Diego Coalition (Transparent and Responsible Use of Surveillance Technology) as the final name. The coalition included Asian Solidarity Collective, Al Otro Lado (a human rights advocacy group for border communities), Universidad Popular, the Council on American-Islamic Relations San Diego, Indivisible, Tech Workers Coalition, We the People, and PoTC, among others. At the first coalition meeting after the June forums, those present shared concerns, brainstormed ways to learn more about the program, and planned a press conference at City Hall to introduce the need for surveillance oversight to the media.

At the City Hall press conference, Geneviéve Jones-Wright, then legal director for PANA, expressed frustration that "there was never any conversation about surveillance issues and privacy interests. We stand here today as community members on Constitution Day to say, 'Respect us and our right to privacy.'” There was also controversy around the political process, with then-Councilmembers Scott Sherman and Chris Cate, both of whom voted for the streetlights, telling the Voice of San Diego that they "were unaware that police had been accessing the cameras." It even reached elections, with City Attorney Mara Elliott being attacked by her only competitor, Cory Briggs, for being negligent for approving the 2016 contract between the city and General Electric [28]. 
The police described their own guidelines, created after community pushback, as "a living document" that will change through community and City Council feedback [84]. However, as pinpointed by investigative journalist Jesse Marx of the Voice of San Diego [84], this "presents an uncomfortable truth: SDPD, not city officials, is setting the terms for how the department should police itself as it accesses data from the streetlights - and it's doing so long after the technology actually went into the field." Should police want to upgrade to add facial recognition or data integration features, it seemed that they could do so and surveil the city without oversight.

Though the Mayor and City Attorney defended the newly politicized program through memos and press conferences, coalition members lobbied City Council members and found them concerned as well. The work of the coalition over the next year would become assembling a collective understanding of the streetlight technology, the contract, the technology's actual uses in San Diego, and the wider ecology of surveillance technology that San Diego residents should be concerned about. The authors of this paper participated in work to support the coalition, responding to needs that arose as we could. It is to this work undertaken in the coalition, and the role of HCI practices, to which we now turn. By reflecting on where and how we were able to strengthen the coalition's work, we suggest ways that HCI knowledge and practice might meet the challenges of computational infrastructures from below.

\section{THREE MOMENTS OF HCI KNOWLEDGE AND PRACTICE IN COALITION}

\subsection{Document reading}

In coalition meetings, community members pooled their knowledge to ask what the future of the streetlights might be given regional policies and historical experiences. One of the authors came from a background working in an AI startup and was experienced reading and negotiating data sharing contracts. He requested the GE Current contract with the city through a Public Records Request [26]. In this initial investigation, we saw language around ownership of data and intellectual property. This language, in the governing contract between GE and the City, specified that GE has, in perpetuity, ownership over the data they manipulate in the course of processing the data to be used by the City. The City retained ownership of the original data, but this is a moot point from a privacy and usability perspective since GE could (by the contract) copy and store the copy while processing it, and retained rights to use it as it pleased. The City and GE also made the metadata from what they claimed to be the entire surveillance infrastructure available to be pulled through their CityIQ APIs, and co-sponsored hackathons with local groups to build out software that was built on pulling that data. Metadata included statistics regarding time, object counts, object positions and directions, where objects were classified as pedestrians, cars parking, cars traversing intersections, and bicycle users - for now. The contract also made brief mention of audio-based gunshot detection, even though the council approved it under the explicit premise of environmental protection.

We also advocated for a view of the system that recognizes the privileging of entrepreneurial citizens [64] over other San Diego residents and visitors in documents such as that in Figure 1. CityIQ was a platform, and GE even had an app store. This meant that the coalition had to be concerned with potential harms not only of the current system but also its extensions as it "unleash[ed] previously untapped smart cities innovation," in the city's words. This has emerged at a time when labor conditions in the United States have shifted in the aftermath of the rise and the popularization of the internet - precarious and contracted work in the gig or sharing economy, the expropriation and accumulation of data by large companies like Facebook and Google, and crises that open up ways for the IT sector to subject young people to generate future value through never-ending practices of building connections, portfolios, and side projects, often for free or through voluntary participation [27]. Metaphors of data as food or fuel (to be tapped) serve to position data as a resource to be consumed [95], and, as Stark and Hoffmann note, discourse around "data as force and resource-point toward additional metaphors rooted in industrial production" [105] - in this case, production to drive innovation forward at the expense of those made more vulnerable.

The shift from the original language regarding community-adjacent environmental concerns led us to imagine whose interests were best served by the framing in those documents. This type of social equity analysis [80] seeks to "identify inequities within as well as between local government jurisdictions" [56] regarding how service is distributed. We sought to better understand what the City and GE could actually do and hoped to do with the technology. In reading the documents, it became clear that despite the "openness" of the system as encoded through the Open Data platform that the APIs are hosted on, citizen participation, inclusion and equity were not the primary concerns. This echoes Sarah Barns' concerns around "the use of open data platforms as proxy versions of citizen consultation or engagement initiatives, resulting in disinvestment from alternate channels" [9]. As well as being an important fact-finding mission, the document readings helped to situate the political realities of the system.

Close examination of the contract and trade publications underscored the City had installed a technology platform that had the potential to livestream to police, support face recognition, and support a developer ecosystem that could install myriad future apps to work upon residents' bodies as data. TRUST San Diego Coalition's response to the City made it clear that a moratorium on streetlight data collection was not enough - TRUST requested a sweeping ordinance that would install transparency, community consultation, and oversight by elected councilmembers for every future acquisition of surveillance technology, including data products and upgrades and new apps for the streetlights. This would govern how the SDPD and other agencies acquire and uses technology [23]. Citizens in New York City, San Francisco and Oakland had successfully resisted city-wide impositions of surveillance technologies through campaigning for oversight processes, and TRUST hoped to follow in their footsteps. The ordinance was a response to an experimental and open future of surveillance technologies for sale and community desire to slow down and intervene in that process.

This came to be a process that, unlike the original contract and technology rollout, played out in the public eye. Attempting to implement a privacy ordinance required navigating through the City council, mobilizing community responses, and even arguments in front of news cameras at campaign events. 


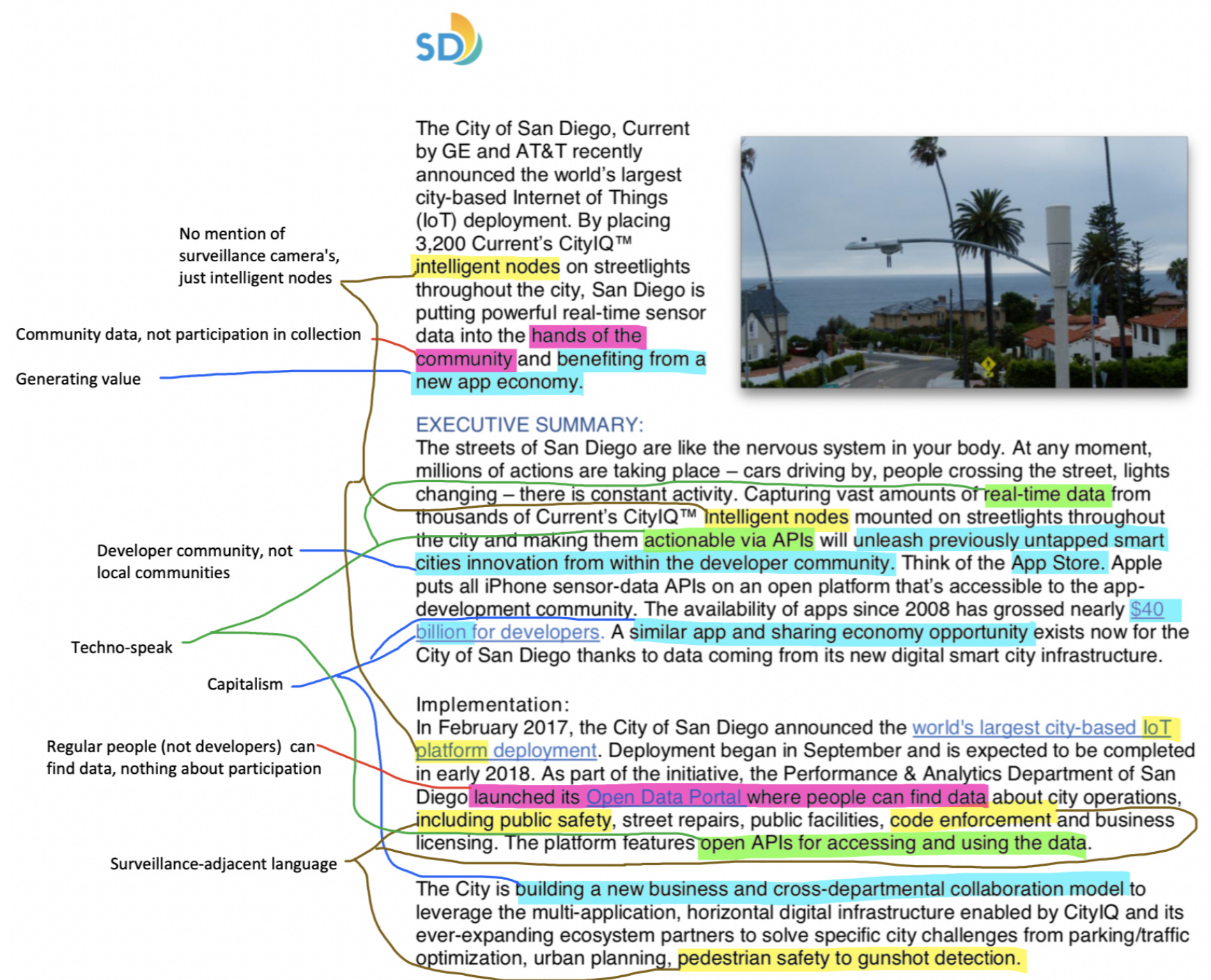

Figure 1: City of San Diego White Paper on GE Current's CityIQ deployment with researcher notes on content [27].

Our work in the coalition put to good use HCI's ways of knowing how to analyze technologies, analyze practices, and articulate the gaps and opportunities between the two [1]. Close reading is a practice of analysis, interpretation, and communication in which we can work with others familiar with, say, city operations or racialized practices, to infer and communicate possible and likely futures. This is the work of collaborative analysis and communication. This is a tactic for challenging the claims made by those above in service of understanding and shaping technologies from below.

\section{2 "Slightly Dystopian" hackathon}

The second tactic reflects a more standard HCI and design practice - one we call a "slightly dystopian hackathon." The hackathon brought a group of seven: a faculty member, three graduate students, an alumna, and an undergraduate, together for two meetings.
The goals were twofold. First, we wanted to engage in speculative design to imagine possible and probable negative uses of the smart streetlights API. This was speculative design in the medium term, drawing on a contextual understanding of San Diego, STEM culture, and the incentives of different organizations in generating creative uses of the API. If civic tech hackathons put residents to work imagining new apps for good, this hackathon put residents to work imagining what we thought different organizations would do based on how they had behaved to date. Second, we found ourselves often telling stories about what the streetlight technology could do in the future when speaking to residents, journalists, and to City Council staff. We felt it would be a powerful public statement to demonstrate rather than narrate harmful use.

This practice of drawing on history to speculate about likely technological futures is one we adopted from coalition members, 
especially Alexander and Dustin Craun, then with the Council for American Islamic relations. While they did not claim insight into the technical details of the AI powered streetlight system, they drew on their historical knowledge of U.S. intelligence activities to estimate how the streetlights might be used to extend those practices. In particular, they reflected on and educated communities about COINTELPRO, an FBI program that surveilled and worked to disrupt the operation of political activist groups, including feminists, communists, and racial justice activists. Tactics included wiretaps, harassment, blackmail, and bombings. Targets included Martin Luther King's Southern Christian Leadership Conference [57] and antiwar activists in San Diego [60]. Alexander and Craun worried that today, Black and Muslim communities and especially activists could be subject to the same kinds of occasionally deadly harassment. Alexander also contextualized surveillance through Simone Brown's analysis that traces the development of surveillance techniques in the US as tied to the policing of black people's mobility in the context of slavery [19]. (Alexander and Craun were prescient as journalists discovered that SDPD did in fact use the cameras to surveil Black Lives Matter marchers the next summer [85].)

While the coalition had worked to explore worst-case scenarios like mass surveillance of activists and gang documentation by livestream, our hackathon explored a wider range of more mundane possibilities. We wanted to explore how the platform might be put to work by entrepreneurial and opportunistic actors and learn about a wider range of latent harms. By illustrating a widened range of latent harms, we could potentially expand the coalition of residents with a stake in exerting oversight over or ridding the city of the streetlights. We utilized the concept of creating provocative designs to engage and challenge (sometimes called 'design noir' [40]) both the dark uses of design and its unintended consequences, with harmful imagined outcomes used to contest political questions.

As the CityIQ API allowed for public access to metadata pulled from the cameras, we decided to ground the speculative design in the existing infrastructure. Members of the research team reached out to different San Diego organizations in the coalition to gather their concerns with how the data from the streetlights (pedestrian, bicycle, and vehicle counts) could possibly be used. Moreover, such conversations underscored the mystification surrounding the CityIQ API and IT infrastructures more generally, where, in the words of one community activist, it was "not clear what the data can be used [for] in the worst-case scenario by itself ... [and whether it] need[s] to be done in conjunction with use of other technology." Grounding the project in these conversations was important to help shape the kinds of scenarios the software demonstrations would present, as well as to think through ways to present the demos that will not do further harm.

The main concerns emerging from these conversations were surveillance, the lack of oversight, and how they factor into broader histories of racialized and religious persecution in the San Diego area. A lawyer in the coalition explained concerns about behavior modification under surveillance - feeling like one can speak less freely when one knows they are being surveilled. She also explained the streetlights extended policing systems that already disproportionately target people of color. Others expressed the concern that while the API data from the streetlights is publicly usable, most do not know what the data actually is and would not have the capacity to monitor its uses (see also [79]).

After conversations with coalition members, we created different mock-ups grounded in the concerns that emerged. Each mock-up characterized bad actors, concerned agents, and public perception. We brainstormed the following app ideas:

- Parking surge pricing that would allow downtown parking companies to get more money out of drivers.

- Gentrification finder that combined data from Yelp and bicycle counts to estimate areas of the city that might be ripe for gentrifying housing development.

- Mosque or synagogue tracker to track time patterns of activity to illustrate intensification of targeting.

- A unhoused or loitering finder using location tracking data to track clusters of people staying in one place.

- Where to Do Crime: an app that could locate the easiest places to engage in criminalized activity according to seclusion from passersby and distance from police stations.

- Someone Walks Alone at Night: an app that could track residents walking alone in the dark, simply for its creepy qualities.

The app ideas were motivated by a desire to connect to concerns already part of the political conversation in San Diego: gentrification, transportation, public safety, and harassment of the unhoused. For each app idea, we also considered likely readings of the app that would harm members of the coalition. An app that suggested secluded places for criminalized activity might trigger among certain people calls for more policing. Policing, however, harmed several communities in the coalition. Similarly, we worried that the app tracking religious congregants might inadvertently build support for the streetlights among members of the public that stigmatize and fear Muslim or Jewish people. We deprioritized demos whose public reception might draw potentially harmful attention to communities in the coalition or set back their political goals.

We created mock-ups of these apps and created a short video [32] that we circulated to the coalition steering committee for asynchronous feedback; synchronous time with busy coalition members is precious and reserved for high priority collective decision making. The comments from the two who responded were enthusiastic. A community mobilizer related how he anticipated others would react: "The homeless ones can get the activists riled up, but I know rich folks will want this. The mosque is tapping a nerve." Both the mobilizer and the Muslim leader suggested additional optional cases: the targeting of activists and the mapping of real time population density in streets that might spark City Council member attention. The mobilizer commented that "Someone Walks Alone At Night is really effective...it refutes all the public safety talking points. This [system] can be used for harm."

We ultimately chose to focus on Someone Walks Home Alone at Night. The group split into two teams, with one team focusing on the speculative portion - how the demo could be designed and used as a storytelling tool and how to make the presentation easy and effective in situations like council meetings, lobbying, or community forums - genres of public political rhetoric from below. This included questions of format, such as whether real time data or mockups would be better. The second team focused on the 


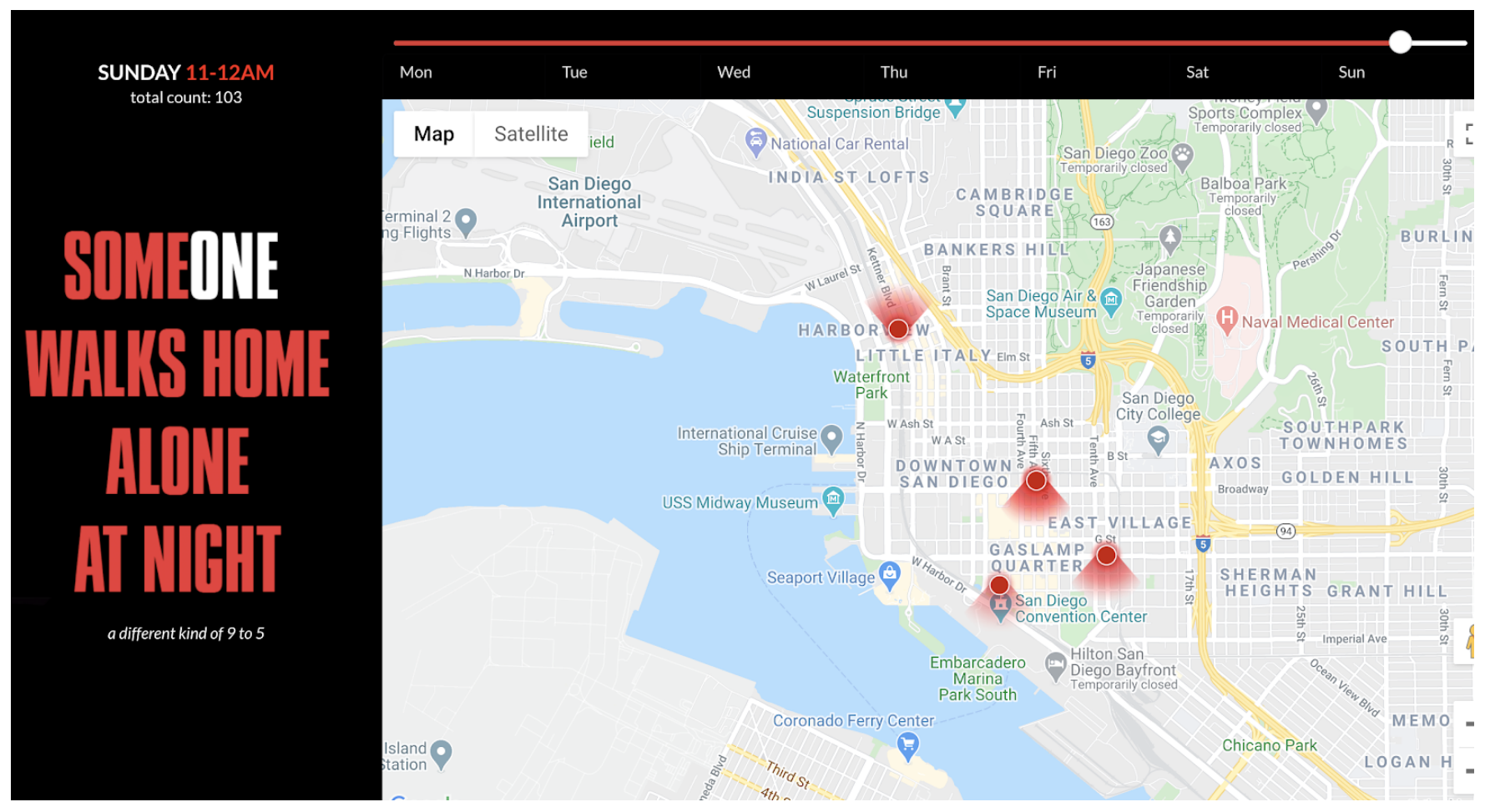

Figure 2: "Slightly Dystopian" demo: "Someone Walks Home Alone at Night" - uses one week of historical pedestrian data pulled from the City of San Diego's publicly accessible CityIQ API [31].

creation of the demo backend using the actual data, setting up data structures to pull streetlight data to support prototyping. Figure 2 shows the demo we created.

This process of imagining and building yielded two lessons about the technology we did not anticipate. First, many of the creepiest or most exploitative potential uses were enabled by real time API data. CityIQ nodes without real time API data, or only for strong justification and with oversight, could be a more cautious approach to deployment. This insight had not come up in coalition discussions. Second, and this became very important, we discovered that just a handful of the over 3,000 streetlight cameras actually reported pedestrian data - less than $0.5 \%$. Other researchers, such as a team at San Diego State University as well as a staff member in the City's Smart and Sustainable Communities department, verified that only a few cameras were reporting data at all [65, 87].

For the coalition, the greatest impact of the slightly dystopian hackathon, as it turned out, was not the demos at all. It was our discovery that the cameras were not reporting the promised mobility and planning data. This led the team to deprioritize making a second, different dystopian demo or working on sharing a storytelling toolkit. Instead, we focused on helping the coalition as they attempted to successful politicize the insight they found useful: the broken data.

\subsection{Public reporting on "Broken Promises"}

What the coalition really wanted was action to stop CityIQ data collection and to bolster the argument for a robust, regulated, and community-informed technology acquisition process. Our demo, a compelling $\mathrm{HCI}$ and industry presentation method, simply was not the most direct way to that goal. A coalition organization director who heard about our findings requested we create a policy report. They requested we deliver the report to City Council members deliberating on the coalition's proposed ordinance, as the ordinance called for oversight over technological efficacy after deployment. More urgently, the Council was about to revise the budget in response to COVID-19 budgetary shortfalls and the coalition saw an opportunity to defund the streetlights based on our findings. This meant we only had 24 hours to hand over a draft report to the Council president, quicker than any research cycle (or rapid prototyping) we had experienced.

The report [65] addressed themes of interest to specific council members, based on our understandings of their agendas and values from prior coalition lobbying. The title, "Broken Promises of Civic Innovation: Technological, Organizational, Fiscal, and Equity Challenges of GE Current CityIQ, hints at these distinct themes. For those who focused on racial equity, we discussed how the CityIQ public data had created no new enterprises, and pointed out that the limits of access to Computer Science education, working capital, and safety nets made app-based innovation viable to only the most privileged. For those on the council who campaigned on good government, we drew on organizational studies of CSCW to discuss the complexities of robust and useful civic data and suggested resources the city needed to have in place to get value from the data. For those who focused on limiting government spending, we discussed the 
ballooning costs of emerging, untried, and now broken technologies as unacknowledged maintenance labor and telecom fees piled on expenses. Finally, the report included a one page summary with our statistics of streetlight locations and explanations of the data failures.

In parallel, we shared our broken cameras findings with a journalist covering surveillance in Voice of San Diego [87], an investigative reporting outlet read closely by City officials and adjacent communities. The following story's headline read "Smart Streetlights Aren't Delivering the Data Boosters Promised." The summary read, "More than three years into San Diego's \$30 million investment, the project is failing to live up to its hype and members of the public trying to work with the data are encountering problems that throw the project's early promotional claims into question." The journalist also interviewed key players in the city's tech innovation scene who affirmed that the open data portion of the platform was broken, even as they hosted civic innovation hackathons around it.

The news story and the university report lent force and legitimacy to the coalition's challenge to the continuous funding of the streetlights. From the dais of a budget hearing, several City Councilmembers cited the camera data failures and our report as one reason to reconsider the city budget for the program. During that hearing's public comments, dozens of citizens - many mobilized through the coalition - called to decry the project during a time of budget shortfall. Notably, community members did not call for the streetlights to be fixed. Instead, people emphasized the failed promises of sustainability and innovation. Any kind of repair to the streetlights was antithetical to needs, anxieties, and fears as articulated by the coalition. The hearing ended with a promise by the Council president to request the cessation of funding to the program.

Coalition members would also cite the report at press conferences and when lobbying council for the ordinance. The report directly confronted claims made by GE Current and City champions, and did so with the institutional legitimacy of a university tech center and scholarly citations behind it. The report assessed their promises and packaged an assessment in an institutionally legitimate format coalition members could use while lobbying. ${ }^{1}$ At one press conference, for example, a coalition speaker cited the report explaining to television cameras that the cameras have not produced the promised jobs. With the report, we were able to consolidate and substantiate through research citations what coalition members knew or suspected. This bolstered the coalition's claims in public spaces.

\section{THE AFTERMATH}

At time of submission, the coalition had won major battles on the way to their desired ordinance. The ordinance had made it through two City Council committees with unanimously supportive votes from Council members from both parties, on its way to a full Council vote in Fall 2020. Council also voted, through several complex steps, to deny the Mayor's attempt to fund the streetlights. As of Sept 9, 2020, the streetlights funding ran out and surveillance feeds to the City are off [45]. In a painful reminder of the problems of

\footnotetext{
${ }^{1}$ Fox and Rosner have also experimented with making research artifacts relevant to
} communities [49]. privatization, the City cannot access the data but the cameras are still rolling. GE Current spun off the smart city division, selling it to a private equity firm who, in turn, sold it to a Florida company called Ubicquia. Ubicquia will not stop the recording until the City pays outstanding bills for the cloud-based surveillance. City Council members have refused to fund the streetlights until the community-engaged surveillance oversight process proposed by the TRUST Coalition is implemented. In December 2020, the full council unanimously voted to adopt the ordinance pending approval by city worker unions. The coalitions work to shape the future continues.

\section{DISCUSSION}

The focus of this work was not to improve, innovate, or even use the publicly available data for forms of social good. Instead, the project aimed to heighten understanding of the relationships between the platform and the communities affected by it. The coalition was able to reveal the brokenness of the system - not as a condition to be repaired, but as an opening towards decisively questioning the value of the streetlights to anyone other than police. Our HCI knowledge contributed to this struggle for democratic control over technology, but in ways that went beyond design, user studies, or systems building. By analyzing legal and technical documents, we helped coalition members speculate about the functions of the technology and the intention of company and city that animated it. By creating "Slightly Dystopian" demos, we began with the desire to demonstrate latent harms but ended with new insights into the messy, material operation of the streetlights API that proved politically consequential. Finally, our report forged a tool with which coalition members confronted the claims through which the City had assembled a coalition supportive of the streetlights including business owners, technologists, and environmental activists. In what follows, we reflect on broader tactics that emerged through our coalitional practices to challenge San Diego's smart city.

\subsection{Pay attention to specific histories and how they organize people's relationships to technology}

Critical HCI movements, such as feminist HCI, have emphasized how technologies cannot be studied without understanding how they are also situated in power relations, institutions, and discourses. These movements often start with a category of domination such as gender, sexuality, or class, and we also underscore it can be fruitful to examine specific histories and situated conditions that affect how people relate to technology. Specific histories grounded and strengthened the rigor of our analyses and speculations. Recall Sahid's questions about how the streetlights might link to JTTF counterinsurgency programs that target her community, or the question posed by a community member concerned that the streetlight cameras could digitize existing police practices that document his neighbors as "gangs." People touched by violence do not have to go as far to speculate about the likely uses of these new technologies.

Learning about fears and anxieties surrounding an unfamiliar but very present piece of city infrastructure enabled us to work on 
demos without exacerbating the vulnerabilities of different communities. Such an approach diverges from more common designing for social good, or its inverse, "designing for the purposes of evil" [104], and moves toward "design in dark times" [69]. Design in dark times suggests that violence is not exceptional. In rejecting the rarity of violence, this approach understands that political struggle also takes place at the level of everyday life, at the level of everyday experience. It is a sign of privilege to be distant from such everyday violence.

Many cities around the world have expanded their integration of the Internet of Things within civic and public space, as documented by scholarship on platform urbanism $[10,11]$, and while there are similarities across these smart city implementations, understanding their particularities - as shaped and reshaped by the people who inhabit them - can help sharpen the relevance of design and HCI practices. Looking at how the histories of a place have organized how people interact with technology and each other can open up ways for researchers to create and dismantle with, instead of designing for, and ultimately to struggle with and struggle together for the control, regulation, and management of these infrastructures.

\subsection{Utilize agonism not for contention's sake, but to create strong collectives}

Smart city technologies are embedded in public space where design cannot help but be at the center of political decisions. The decisions being made about what and how to design, however, occur in government and industry spaces [89] that move those decisions away from those being impacted - those who are being measured, recorded, surveilled, audited, and predicted in everyday life. Mulligan's “Saving Governance By Design” proposes methods for "decision makers" to protect democratic values and processes, addressing actors already "above" - able to make decisions about technology and open to broader democratic inclusion. Adversarial design, in contrast, approaches democracy from a standpoint of struggle over meanings, norms, and values in society at large [33]. Agonism or confrontation through opposition, Mouffe and Laclau argue, creates better democratic knowledge [74]. They note that the presence of many contestations enlivens democracy, as this means many are inspired to actively participate in the building and maintenance of a democratic society. Adversarial design calls on designers to participate in democracy through provocative and conflictual engagement [34]. In this view, design is a means to challenge conventional approaches to an issue, and contestation is a goal that designers ought to strive for.

In our San Diego case, the creation of an adversarial space was not fronted by designers. Instead, we as HCI researchers worked as part of a coalition with community voices to build adversarial technologies and interpretations informed by the ways in which the wider coalition was already causing friction and introducing their concerns and knowledge into the public sphere. As one example, we focused on the "Someone Walks Alone at Night" app due to an argument the coalition was driving in public debate. In particular, they pushed back at claims that surveillance creates public safety, common in the rhetoric surrounding the streetlights. The demo told a startling story that an open data API could be used in ways that actually harm public safety. Though we did not show the demo to council members in the end, we did explain the demos to them as a powerful example to challenge police's claims about public safety, leveraging our relative expertise in technology.

In order to engage in agonistic democracy, we needed spaces in coalition to work with communities formulating and articulating knowledge that ran counter to hegemonic, or dominant, ideas about safety. Also, agonistic participation can take an emotional toll and require spaces of support, joy, and healing. We found these in our playful but serious spaces of HCI coalition work as well as in some relationships with people in the coalition. We call attention to the importance of collective spaces by drawing on Nancy Fraser's argument on the importance of the multiplicity of arenas of discussion, especially where groups can circulate counterdiscourses. These sites, called counterpublics, not only open up places of discussion to those excluded from the decision making of powerful actors particularly local government and large tech corporations - but also can redirect these discussions to wider publics [50]. By using adversarial methods in coalition, agonism is focused towards the articulations generated by communities from below.

\subsection{Be accountable to long-term relationships}

Adversarial design, as we noted above, underscores the importance of contestation through creation, and how this practice is central to democratic processes. While such agonistic moments can enrich participation in civic life, it is also important to articulate who you are standing with, and how you remain in coalition. This tactic, then, involves being accountable to sustaining long-term relationships. As Reagon reminds us, coalition can bring together people who society might otherwise pit against one another [103]. Long term coalition relationships will inevitably result in conflict; in social justice work, conflict is a sign that real tensions in society are revealing themselves in the work. Rather than run away, these conflicts offer opportunities to learn, transform ourselves, and do justice work not just in the changes to the world outside but to the relationships within the coalition. Conflict and reflexivity, as Dombrowski, Harmon, and Fox argue, are central commitments for an HCI working towards social justice [35], and we found it vital to be learning from and on the ground, and to be in relationships with community leaders and organizers that go beyond the existence of any project. By conflict, we do not mean fighting. We mean the tensions that arise as people work through differences to find a way forward. The last author's long-term participation in Tech Workers Coalition was vital as a relational building block in this coalitional work. This move calls for an enduring and slow HCI that does not take for granted the infrastructures, technologies, communities, and people that it embeds itself in.

Long term accountability is essential to practicing an ethics of care $[62,109]$ and humility (both of which we will further unpack in the succeeding tactics). Accountabilities to the coalition took precedent over accountability to our disciplines and professions. When we work in industry or the university, we can recognize the way we ourselves rarely manage or control these spaces and the strategies employed by them. Many of us are below as academic or industrial workers. We can draw on those positions to find ways of relating to technologies and our neighbors that are already there but often not recognized as we prioritize the goals of our employers. What 
can we learn by listening to our ethical itch and inquiring about our own experiences of oppression or exploitation, drawing on those techno-ethics and techno-affects to find new relationships to technology and our communities [5]? These forms of self-reflection and even self-critique lay the groundwork for entering into and sustaining long-term relationships and building coalitions, organizing on the basis of a wider set of truths accountable to but also different from those we organize with.

\subsection{Let people re-narrate the work for different contexts of political action}

Following the previous section's point on exceeding accountabilities from above, this next tactic deals with the afterlives of $\mathrm{HCI}$ projects. The designed artifacts - whether an app, a prototype, or a fictional product or service - sometimes matter less than what can be realized through their imagining and making. In our example, the broken cameras became the most interesting point to the widest group of people, and coalition members frequently deployed the argument about wasted tax dollars as they worked to gain support across the political spectrum. Instead of designing for the TRUST coalition, we speculatively interpreted, designed, and refuted with them. We worked with them not out of an intellectual interest in surveillance, but out of commitments we brought to the project: for some, a desire to seize democratic control over technologies where we live, for others an antipathy towards mass surveillance, and yet for others a frustration with policing in urban space. We developed our inquiry according to these situated differences, not from a view from nowhere [58]. Coalition members were able to use what they needed from the process and request help from us and one another in tailoring artifacts and documents to those needs. Our long-term relationships meant we trusted them to push back on us when our contributions to the coalition needed revision to work towards the shared goal. And we trusted them to use our work in ways they saw fit, and in ways we did not imagine as coalition members improvised in processes of community education, lobbying, and argument. We did not control the meanings and uses of our demo or report; others who used these artifacts made highlighted different aspects as relevant to the situation they navigated moment to moment. These re-narrations not only serve to flexibly challenge the rhetoric of stakeholders from above - such as City Council, tech companies, and financial institutions - but also, like the broken streetlights, enable activists to unsettle agreements and open political space.

\subsection{Interrogate the black box in solidarity}

As HCI researchers, we are part of a technical community with skills that can be of service to community organizing. In the case of the smart city, this meant being able to access public programmer tools, experiment with available data, and relay information in ways that were understandable and relevant to different communities and their different stakes. We can imagine future scenarios enabled by a particular technical infrastructure. We can infer how technical affordances and configurations can support or erode socially- or individually-held values. We contributed this work in a variety of venues. We asked questions at community meetings, participated in coalition strategy discussions, wrote reports, spoke with local journalists, sat on community education panels, and even organized some ourselves. This paper offers only a sample of our activities in this paper for concerns of length.

Researchers in HCI are often better placed than other coalition members to begin prying open the black box of technology, especially when that black box is protected by private sector interests (e.g. trade secrets). We are more likely to have work experiences and social networks inside the places these technologies are built. We also study how to make those algorithms visible through techniques like auditing, comparison, and code reading. The techniques developed, both in our own and in allied fields, for examining black boxes - Angèle Christin's methods for comparing algorithms to gain insight into them [20], or Nick Seaver's idea that algorithmic enactments can be read through the networks they animate and interact with [100] - offer ways to explore how computational systems should be relevant and even politicized within our communities. HCI practitioners can move beyond the role of an expert mediator between interests above and below to one where we use the breadth of our capacities to affect and interpret technology as parts of coalitions working from below.

To interrogate in solidarity means going beyond the questions that we, our field, or our employers find interesting. It means taking an interest in what others' want or need to know. It also means recognizing that others have insights into the black box and its effects that we do not, or that we may be shielded from. Solidarity requires humility.

\subsection{Exercise humility}

This last tactic is an exercise in humility, and emphasizes that everyone has gaps in their skills and knowledge. In order to get at the heart of any issue, learning with and from one another is crucial. Recognize what other people know about sociotechnical systems knowledge, in particular, that comes from practice - and reflexively assess and learn the limitations of your own situated perspective $[35,58]$. Such reflexivity goes beyond reflection on researchers' own work and positioning. It takes into account how to best work with tensions that arise from different histories that situate people and their projects. It seeks the advantage of the diversity and differences among those struggling together. For example, when we first got involved in the coalition, we were attuned to the politics of innovation and tech gentrification, as well as concerns about privacy in democracy. Our partners in the coalition deepened our understanding a great deal by placing these technologies in the context of policing and counter-insurgency, both in San Diego and globally. These conversations deepen the rigor of any project, but more importantly, they deepen the project's stakes: who do you build coalition with, what do you have to learn to work together, what is at stake in doing so? Writing in context of patient-physician relations, Ruha Benjamin has called for "cultural humility" in the face of expertlayperson power dynamics mediated by race and gender [14]. This cultural humility builds what Fischer expanded on as the concept of "mutual symmetry of ignorance" [46], focusing on practitioners incorporating a "lifelong commitment to self-evaluation and selfcritique, to redressing the power imbalances ... and to developing mutually beneficial and non-paternalistic... advocacy partnerships with communities" [14]. 


\section{CONCLUSION}

These tactics from below reflect our hope for futures that can only be realized through collaboration and through forms of political struggle that exceed the limits of project duration, grant funding, and other bureaucratic hurdles common in both industry and academia. They also exceed what governments or companies might work towards if left to operate as usual. To attain these alternative futures, people must organize together to gain input, oversight, and control over the acquisition, configuration, maintenance, and regulation of technologies. For this, we must act with others in solidarity, with accountability, and with humility.

This paper has offered a variety of tactics by which we, as HCI researchers, centered community organizing to build power over technology when power had not been given. HCI ways of knowing were helpful as the coalition tried to interpret technological specifications and contracts, imagine probable harms to communities, and counter mistaken or misleading city claims about the technology. $\mathrm{HCI}$ can offer more than design and redesign in making real-world technologies serve purposes of human dignity and flourishing decided by those most affected [37]. We did not know what tactics were needed as we began this work. These tactics emerged through our collaboration in the coalition and will continue to be refined and iterated as we continue this work.

The tactics developed through this surveillance regulation coalition should apply to other struggles over public computation as well. If the purpose of HCI was to make technology good for people, our field must expand its view of how it works to engage with political institutions, as well as the political nature of visions of technological good. This paper offers counter-practices that engage both while building power from below. We hope to inspire others to document and reflect on those stories from other struggles over technology beyond smart cities and surveillance.

This paper makes several contributions: a robust case study of an emerging smart city and the different stakeholders in struggle over its form, an argument for the importance of political organizing from below by engaging in technical work beyond design, and workable tactics that articulate alternative roles and commitments for HCI researchers. We do this work for our own communities and in solidarity with those with different histories and situations so the technologies we live among make our worlds more habitable for us and those we care for.

\section{ACKNOWLEDGMENTS}

We thank participants in the San Diego TRUST Coalition, especially steering committee members Khalid Alexander, Dustin Craun, Seth Hall, Geneviéve Jones Wright, DJ Kuttin Kandi, Jean Huy Tran, and Homayra Yusufi. Andrea St. Julian, Jesse Marx, Katy Stegall, Eric Busboom, and Dhaha Nur also helped us understand the APIs and city bureaucracies. Lauran Irion helped with the hackathon. Sucheta Ghoshal, Carl DiSalvo, Anne Jonas, Jenna Burrell, Alyssa Tate and members of Feminist Labor Lab and the Design Lab provided comments that improved this work. UC Humanities Research Institute brought together Feminist STAR Lab (Christoph Hanssmann, Leslie Quintanilla, Saiba Varma, Kalindi Vora, Sal Zarate) to experiment with STEM and feminist methods and theories. Feedback from anonymous reviewers helped us improve this paper significantly. This material is based upon work supported by the National Science Foundation Graduate Research Fellowship under Grant No. DGE 1752814. Any opinion, findings, and conclusions or recommendations expressed in this material are those of the authors(s) and do not necessarily reflect the views of the National Science Foundation. Friends and loved ones cared for us in many ways that enabled this work.

\section{REFERENCES}

[1] Mark S Ackerman. 2000. The intellectual challenge of CSCW: the gap between social requirements and technical feasibility. Human-Computer Interaction 15, 2-3 (2000), 179-203.

[2] Jon Agar. 2003. The Government Machine: A Revolutionary History of the Computer. MIT Press. Google-Books-ID: ZcnxCwAAQBAJ.

[3] Saul David Alinsky. 1989. Rules for radicals: a practical primer for realistic radicals (vintage books ed ed.). Vintage Books, New York.

[4] Morgan G Ames. 2019. The charisma machine: The life, death, and legacy of One Laptop per Child. Mit Press.

[5] Sareeta Amrute. 2019. Of Techno-Ethics and Techno-Affects. Feminist Review 123, 1 (Nov. 2019), 56-73. https://doi.org/10.1177/0141778919879744

[6] Nikhil Anand, Akhil Gupta, and Hannah Appel. 2018. The promise of infrastructure. Duke University Press.

[7] Mariam Asad. 2019. Prefigurative Design as a Method for Research Justice. Proceedings of the ACM on Human-Computer Interaction 3, CSCW (Nov. 2019), 200:1-200:18. https://doi.org/10.1145/3359302

[8] Liam J. Bannon and Pelle Ehn. 2012. Design Matters in Participatory Design. In Routledge International Handbook of Participatory Design. Routledge. https: //doi.org/10.4324/9780203108543.ch3

[9] Sarah Barns. 2016. Mine your data: open data, digital strategies and entrepreneurial governance by code. Urban Geography 37, 4 (May 2016), 554-571. https://doi.org/10.1080/02723638.2016.1139876

[10] Sarah Barns. 2018. Smart cities and urban data platforms: Designing interfaces for smart governance. City, Culture and Society 12 (March 2018), 5-12. https: //doi.org/10.1016/j.ccs.2017.09.006

[11] Sarah Barns. 2018. We Are All Platform Urbanists Now. https://www. mediapolisjournal.com/2018/10/we-are-all-platform-urbanists-now/

[12] Eric P.S. Baumer and M. Six Silberman. 2011. When the implication is not to design (technology). In Proceedings of the SIGCHI Conference on Human Factors in Computing Systems (CHI '11). Association for Computing Machinery, New York, NY, USA, 2271-2274. https://doi.org/10.1145/1978942.1979275

[13] Eevi Beck. 2002. P for Political: Participation is Not Enough. Scandinavian fournal of Information Systems 14, 1 (Jan. 2002). https://aisel.aisnet.org/sjis/ vol14/iss $1 / 1$

[14] Ruha Benjamin. 2013. People's science: bodies and rights on the stem cell frontier. Stanford University Press, Stanford, California.

[15] Ruha Benjamin. 2019. Race after technology: abolitionist tools for the new fim code. Polity, Medford, MA.

[16] Jim Benson. 2017. San Diego to Deploy World's Largest City-Based 'Internet of Things' Platform. Mayor Faulconer Live! \#smartcities \#IoT. https://www.pscp. tv/jbensons/1eaJbPynBYdKX

[17] Harry Bregazzi and Mark Jackson. 2018. Agonism, critical political geography, and the new geographies of peace. Progress in Human Geography 42, 1 (Feb. 2018), 72-91. https://doi.org/10.1177/0309132516666687 Publisher: SAGE Publications Ltd.

[18] Adrienne M. Brown. 2017. Emergent strategy. AK Press, Chico, CA.

[19] Simone Browne. 2015. Dark Matters: On the Surveillance of Blackness. (Sept. 2015). https://doi.org/10.1215/9780822375302

[20] Angèle Christin. 2020. The ethnographer and the algorithm: beyond the black box. Theory and Society 49, 5 (Oct. 2020), 897-918. https://doi.org/10.1007/ s11186-020-09411-3

[21] Marika Cifor, Patricia Garcia, T. L. Cowan, Jasmine Rault, Tonia Sutherland, Anita Say Chan, Jennifer Rode, Anna Lauren Hoffmann, Niloufar Salehi, and Lisa Nakamura. 2019. Feminist data manifest-no. https://www.manifestno.com/

[22] Danielle Citron. 2015. Open Code Governance. University of Chicago Legal Forum 2008, 1 (Dec. 2015). https://chicagounbound.uchicago.edu/uclf/vol2008/iss1/9

[23] City News Service 2020. Public Safety Committee Moves Surveillance Ordinances to Full Council. https://www.kpbs.org/news/2020/jul/15/public-safetycommittee-surveillance-ordinance/

[24] City of San Diego 2015. City of San Diego Open Data Policy. http://dockets.sandiego.gov/sirepub/cache/2/fsgblpbzckps0ysve2gfqja4/ 75784609162020074114368.PDF

[25] City of San Diego 2017. Open Data Implementation Update 2017. https://datasd.gitbooks.io/open-data-implementation-update2017/content/main/custom_portal.html 
[26] City of San Diego 2018. Request \#18-3940. https://sandiego.nextrequest.com/ requests $/ 18-3940$

[27] City of San Diego 2020. City of San Diego - Digital Infrastructure. https://www.voiceofsandiego.org/wp-content/uploads/2020/02/SanDiego-Digital-Infrastructure-.pdf

[28] Morgan Cook. 2019. Protesters call for San Diego to suspend 'smart streetlight' technology, citing privacy concerns. https://www.sandiegouniontribune.com/ news/watchdog/story/2019-09-17/protesters-call-for-san-diego-to-suspendsmart-streetlight-technology-ci-privacy-concerns

[29] Sasha Costanza-Chock. 2020. Design justice: community-led practices to build the worlds we need. The MIT Press, Cambridge, MA.

[30] Mike Davis. 2006. City of Quartz: Excavating the Future in Los Angeles (New Edition). Verso Books. Google-Books-ID: 19rscdvGCBcC.

[31] demo 2020. Someone Walks Home Alone. simsinght.github.io/alone/

[32] demo 2020. Someone Walks Home Alone - Video Demonstration. https: //doi.org/10.5281/zenodo.4433142

[33] Carl DiSalvo. 2012. Adversarial design. MIT Press, Cambridge, Mass.

[34] Carl DiSalvo, Tom Jenkins, and Thomas Lodato. 2016. Designing Speculative Civics. In Proceedings of the 2016 CHI Conference on Human Factors in Computing Systems (CHI '16). Association for Computing Machinery, New York, NY, USA, 4979-4990. https://doi.org/10.1145/2858036.2858505

[35] Lynn Dombrowski, Ellie Harmon, and Sarah Fox. 2016. Social Justice-Oriented Interaction Design: Outlining Key Design Strategies and Commitments. In Proceedings of the 2016 ACM Conference on Designing Interactive Systems (DIS '16). Association for Computing Machinery, New York, NY, USA, 656-671. https //doi.org/10.1145/2901790.2901861

[36] Paul Dourish. 2019. User experience as legitimacy trap. Interactions 26, 6 (Oct 2019), 46-49. https://doi.org/10.1145/3358908

[37] Paul Dourish. 2021. The Allure and the Paucity of Design: Cultures of Design and Design in Culture. Human-Computer Interaction 36, 1 (Jan. 2021), 52-72. https://doi.org/10.1080/07370024.2018.1469410

[38] John S. Dryzek. 2005. Deliberative Democracy in Divided Societies: Alternatives to Agonism and Analgesia. Political Theory 33, 2 (April 2005), 218-242. https: //doi.org/10.1177/0090591704268372

[39] Cody Dulaney. 2020. San Diego Activists Join Call To Stop Adding People To State's Gang Database. KPBS Public Media (June 2020). https://www.kpbs.org/ news/2020/jun/30/san-diego-activists-join-call-stop-adding-people-s/

[40] Anthony Dunne and Fiona Raby. 2001. Design noir: the secret life of electronic objects. Birkhäuser, Basel.

[41] Chris Elsden, David Chatting, Abigail C. Durrant, Andrew Garbett, Bettina Nissen, John Vines, and David S. Kirk. 2017. On Speculative Enactments. In Proceedings of the 2017 CHI Conference on Human Factors in Computing Systems (CHI '17). Association for Computing Machinery, New York, NY, USA, 5386-5399. https://doi.org/10.1145/3025453.3025503

[42] Sheena Erete and Jennifer O. Burrell. 2017. Empowered Participation: How Citizens Use Technology in Local Governance. In Proceedings of the 2017 CH Conference on Human Factors in Computing Systems (CHI '17). Association for Computing Machinery, New York, NY, USA, 2307-2319. https://doi.org/10. $1145 / 3025453.3025996$

[43] Virginia Eubanks. 2018. Automating Inequality: How High-Tech Tools Profile, Police, and Punish the Poor. St. Martin's Publishing Group.

[44] James Ferguson and Akhil Gupta. 2004. Spatializing States: Toward an Ethnography of Neoliberal Governmentality. American Ethnologist 29, 4 (Oct. 2004), 981-1002. http://www.anthrosource.net/doi/abs/10.1525/ae.2002.29.4.981

[45] Teri Figueroa. 2020. Mayor orders San Diego's Smart Streetlights turned off until surveillance ordinance in place. https://www.sandiegouniontribune. com/news/public-safety/story/2020-09-09/mayor-orders-san-diegos-smartstreetlights-turned-off-until-surveillance-ordinance-in-place

[46] G. Fischer. 2000. Symmetry of ignorance, social creativity, and meta-design Knowledge-Based Systems 13, 7-8 (Dec. 2000), 527-537. https://doi.org/10.1016/ S0950-7051(00)00065-4

[47] Michel Foucault. 1982. The Subject and Power. Critical Inquiry 8, 4 (1982) 777-795. http://www.jstor.org/stable/1343197 ArticleType: primary_article / Full publication date: Summer, 1982 / Copyright $\odot 1982$ The University of Chicago Press.

[48] Diane L. Fowlkes. 1997. Moving from Feminist Identity Politics To Coalition Politics Through a Feminist Materialist Standpoint of Intersubjectivity in Gloria Anzaldúa's Borderlands/La Frontera: The New Mestiza. Hypatia 12, 2 (1997), 105-124. https://doi.org/10.1111/j.1527-2001.1997.tb00021.x

[49] Sarah Fox and Daniela K Rosner. 2016. Continuing the dialogue: Bringing research accounts back into the field. In Proceedings of the 2016 CHI Conference on Human Factors in Computing Systems. 1426-1430.

[50] Nancy Fraser. 1990. Rethinking the Public Sphere: A Contribution to the Critique of Actually Existing Democracy. Social Text 25/26 (1990), 56. https://doi.org/ $10.2307 / 466240$

[51] Batya Friedman, Peter H. Kahn, and Alan Borning. 2008. Value Sensitive Design and Information Systems. In The Handbook of Information and Computer Ethics. John Wiley \& Sons, Ltd, 69-101. https://doi.org/10.1002/9780470281819.ch4
[52] Sucheta Ghoshal, Rishma Mendhekar, and Amy Bruckman. 2020. Toward a Grassroots Culture of Technology Practice. Proceedings of the ACM on HumanComputer Interaction 4, CSCW1 (May 2020), 054:1-054:28. https://doi.org/10. $1145 / 3392862$

[53] Antonio Gramsci and Quintin Hoare. 1985. Selections from the prison notebooks of Antonio Gramsci (8. pr ed.). International Publ, New York.

[54] Ben Green. 2019. The smart enough city: putting technology in its place to reclaim our urban future.

[55] Melissa Gregg. 2015. Hack for good: Speculative labour, app development and the burden of austerity. The Fibreculture fournal 25 (2015), 185-202. https: //doi.org/10.15307/fcj.25.186.2015

[56] Mary E. Guy and Sean A. McCandless. 2012. Social Equity: Its Legacy, Its Promise. Public Administration Review 72, s1 (2012), S5-S13. https://doi.org/10. 1111/j.1540-6210.2012.02635.x

[57] Peter Christian Hall. 2010. Martin Luther King Jr.: Remembering With a New Cointelpro. https://www.huffpost.com/entry/martin-luther-king-jr-rem_b_ 426841 Section: Politics.

[58] Donna Haraway. 1988. Situated Knowledges: The Science Question in Feminism and the Privilege of Partial Perspective. Feminist Studies 14, 3 (1988), 575-599. https://doi.org/10.2307/3178066

[59] Sara Heitlinger, Nick Bryan-Kinns, and Janis Jefferies. 2013. Sustainable HCI for grassroots urban food-growing communities. In Proceedings of the 25th Australian Computer-Human Interaction Conference: Augmentation, Application, Innovation, Collaboration (OzCHI '13). Association for Computing Machinery, New York, NY, USA, 255-264. https://doi.org/10.1145/2541016.2541023

[60] Everett Holles. 1975. A.C.L.U. Says F.B.I. Funded 'Army' To Terrorize Young War Dissidents (Published 1975). The New York Times (June 1975). https://www.nytimes.com/1975/06/27/archives/aclu-says-fbi-fundedarmy-to-terrorize-young-war-dissidents.html

[61] Alexis Hope, Catherine D'Ignazio, Josephine Hoy, Rebecca Michelson, Jennifer Roberts, Kate Krontiris, and Ethan Zuckerman. 2019. Hackathons as Participatory Design: Iterating Feminist Utopias. In Proceedings of the 2019 CHI Conference on Human Factors in Computing Systems (CHI '19). Association for Computing Machinery, New York, NY, USA, 1-14. https://doi.org/10.1145/3290605.3300291

[62] Dorothy Howard and Lilly Irani. 2019. Ways of Knowing When Research Subjects Care. In Proceedings of the 2019 CHI Conference on Human Factors in Computing Systems (CHI '19). Association for Computing Machinery, New York, NY, USA, 1-16. https://doi.org/10.1145/3290605.3300327

[63] Liesbeth Huybrechts, Henric Benesch, and Jon Geib. 2017. Institutioning: Participatory Design, Co-Design and the public realm. CoDesign 13, 3 (July 2017), 148-159. https://doi.org/10.1080/15710882.2017.1355006

[64] Lilly Irani. 2019. Chasing innovation: making entrepreneurial citizens in modern India. Princeton University Press, Princeton, New Jersey ; Oxford, United Kingdom.

[65] Lilly Irani and Cedric Deslandes Whitney. 2020. Broken Promises of Civic Innovation: Technological, Organizational, Fiscal, and Equity Challenges of GE Current CityIQ. https://doi.org/10.5281/zenodo.4434752

[66] Lilly C Irani and M Six Silberman. 2013. Turkopticon: Interrupting worker invisibility in amazon mechanical turk. In Proceedings of the SIGCHI conference on human factors in computing systems. 611-620.

[67] Nicola J Bidwell. 2020. Wireless in the Weather-world and Community Networks Made to Last. In Proceedings of the 16th Participatory Design Conference 2020 - Participation(s) Otherwise - Volume 1 (PDC '20). Association for Computing Machinery, New York, NY, USA, 126-136. https://doi.org/10.1145/3385010. 3385014

[68] Steven J. Jackson, Tarleton Gillespie, and Sandy Payette. 2014. The Policy Knot: Re-integrating Policy, Practice and Design in Cscw Studies of Social Computing. In Proceedings of the 17th ACM Conference on Computer Supported Cooperative Work \& Social Computing (CSCW'14). ACM, New York, NY, USA, 588-602. https://doi.org/10.1145/2531602.2531674

[69] Mahmoud Keshavarz and Ramia Maze. 2013. Design and Dissensus: Framing and Staging Participation in Design Research. Design Philosophy Papers 11, 1 (May 2013), 7-29. https://doi.org/10.2752/089279313X13968799815994

[70] Os Keyes, Josephine Hoy, and Margaret Drouhard. 2019. Human-Computer Insurrection. (2019).

[71] Rob Kitchin, Paolo Cardullo, and Feliciantonio Cesare Di. 2019. Citizenship, Justice, and the Right to the Smart City. In The Right to the Smart City, Paolo Cardullo, Cesare Di Feliciantonio, and Rob Kitchin (Eds.). Emerald Publishing Limited, 1-24. https://doi.org/10.1108/978-1-78769-139-120191001

[72] Sandjar Kozubaev, Chris Elsden, Noura Howell, Marie Louise Juul Søndergaard, Nick Merrill, Britta Schulte, and Richmond Y. Wong. 2020. Expanding Modes of Reflection in Design Futuring. In Proceedings of the 2020 CHI Conference on Human Factors in Computing Systems (CHI '20). Association for Computing Machinery, New York, NY, USA, 1-15. https://doi.org/10.1145/3313831.3376526

[73] Maroš Krivý. 2018. Becoming-Platform, the Urban and the City. https://www. mediapolisjournal.com/2018/10/becoming-platform/

[74] Ernesto Laclau and Chantal Mouffe. 1985. Hegemony and socialist strategy: towards a radical democratic politics (second edition ed.). Verso, London. 
[75] Agnieszka Leszczynski. 2016. Speculative futures: Cities, data, and governance beyond smart urbanism. Environment and Planning A: Economy and Space 48, 9 (Sept. 2016), 1691-1708. https://doi.org/10.1177/0308518X16651445

[76] Silvia Lindtner and Seyram Avle. 2017. Tinkering with Governance: Technopolitics and the Economization of Citizenship. Proceedings of the ACM on Human-Computer Interaction 1, CSCW (Dec. 2017), 70:1-70:18. https: //doi.org/10.1145/3134705

[77] Silvia Lindtner, Shaowen Bardzell, and Jeffrey Bardzell. 2018. Design and Intervention in the Age of "No Alternative". Proceedings of the ACM on HumanComputer Interaction 2, CSCW (Nov. 2018), 109:1-109:21. https://doi.org/10 $1145 / 3274378$

[78] Thomas Lodato and Carl DiSalvo. 2018. Institutional constraints: the forms and limits of participatory design in the public realm. In Proceedings of the 15th Participatory Design Conference on Full Papers - PDC '18. ACM Press, Hasselt and Genk, Belgium, 1-12. https://doi.org/10.1145/3210586.3210595

[79] Thomas James Lodato and Carl DiSalvo. 2016. Issue-oriented hackathons as material participation. New Media \& Society 18, 4 (April 2016), 539-557. https: //doi.org/10.1177/1461444816629467

[80] William H. Lucy, Dennis Gilbert, and Guthrie S. Birkhead. 1977. Equity in Local Service Distribution. Public Administration Review 37, 6 (1977), 687-697. https://doi.org/10.2307/975337

[81] Peter Lyle, Mariacristina Sciannamblo, and Maurizio Teli. 2018. Fostering Commonfare. Infrastructuring Autonomous Social Collaboration. In Proceedings of the 2018 CHI Conference on Human Factors in Computing Systems (CHI '18). Association for Computing Machinery, New York, NY, USA, 1-12. https://doi. org $/ 10.1145 / 3173574.3174026$

[82] Dave Maass. 2019. San Diego's Face Recognition Program and Collaboration with ICE Needs to Stop. https://www.eff.org/deeplinks/2019/10/san-diegosface-recognition-program-needs-stop

[83] Mirca Madianou. 2020. A Second-Order Disaster? Digital Technologies During the COVID-19 Pandemic. Social Media + Society 6, 3 (July 2020), 205630512094816. https://doi.org/10.1177/2056305120948168

[84] Jesse Marx. 2019. Public, Council Were in the Dark on Police Access to 'Smart' Streetlights. https://www.voiceofsandiego.org/topics/public-safety/publiccouncil-were-in-the-dark-on-police-access-to-smart-streetlights/

[85] Jesse Marx. 2020. Police Used Smart Streetlight Footage to Investigate Protestors. https://www.voiceofsandiego.org/topics/public-safety/the-missioncreep-of-smart-streetlights/

[86] Jesse Marx. 2020. Smart Streetlights Are Now Exclusively a Tool for Police. https://www.voiceofsandiego.org/topics/public-safety/smart-streetlightsare-now-exclusively-a-tool-for-police/

[87] Jesse Marx. 2020. Smart Streetlights Aren't Delivering the Data Boosters Promised. https://www.voiceofsandiego.org/topics/government/getting-ridof-san-diegos-smart-streetlights-will-be-costly

[88] Shannon Mattern. 2016. Instrumental City: The View from Hudson Yards, circa 2019. Places fournal (April 2016). https://doi.org/10.22269/160426

[89] Deirdre K. Mulligan and Kenneth A. Bamberger. 2018. Saving Governance-by Design. SSRN Scholarly Paper ID 3175017. Social Science Research Network, Rochester, NY. https://papers.ssrn.com/abstract $=3175017$

[90] Ana Muñiz. 2015. Police, power, and the production of racial boundaries. Rutgers University Press.

[91] William Odom, John Zimmerman, Scott Davidoff, Jodi Forlizzi, Anind K. Dey, and Min Kyung Lee. 2012. A fieldwork of the future with user enactments. In Proceedings of the Designing Interactive Systems Conference (DIS '12). Association for Computing Machinery, New York, NY, USA, 338-347. https://doi.org/10. $1145 / 2317956.2318008$

[92] Judith S. Olson and Wendy A. Kellogg. 2014. Ways of Knowing in HCI. Vol. 2. Springer, New York.

[93] Davide Panagia. [n.d.]. The Force of Political Argument. Political Theory 32, 6 (Dec. [n. d.]), 825-848. https://doi.org/10.1177/0090591704265729

[94] Frank Pasquale. 2015. The black box society: the secret algorithms that control money and information. Harvard University Press, Cambridge.

[95] Cornelius Puschmann and Jean Burgess. 2014. Big Data, Big Questions Metaphors of Big Data. International Journal of Communication 8, 0 (June 2014), 20. https://ijoc.org/index.php/ijoc/article/view/2169 Number: 0.
[96] Matt Ratto and Megan Boler. 2014. DIY Citizenship: Critical Making and Social Media. MIT Press.

[97] Pedro Reynolds-Cuéllar and Daniela Delgado Ramos. 2020. CommunityBased Technology Co-Design: Insights on Participation, and the Value of the \&\#x201c;Co\&\#x201d;. In Proceedings of the 16th Participatory Design Conference 2020 - Participation(s) Otherwise - Volume 1 (PDC '20). Association for Computing Machinery, New York, NY, USA, 75-84. https://doi.org/10.1145/3385010.3385030

[98] Jathan Sadowski. 2020. Too Smart: How Digital Capitalism is Extracting Data, Controlling Our Lives, and Taking Over the World. The MIT Press. https: //doi.org/10.7551/mitpress/12240.001.0001

[99] Nitin Sawhney and Anh-Ton Tran. 2020. Ecologies of Contestation in Participatory Design. In Proceedings of the 16th Participatory Design Conference 2020 -
Participation(s) Otherwise - Volume 1 (PDC '20). Association for Computing Machinery, New York, NY, USA, 172-181. https://doi.org/10.1145/3385010.3385028

[100] Nick Seaver. 2017. Algorithms as culture: Some tactics for the ethnography of algorithmic systems. Big Data \& Society 4, 2 (Dec. 2017), 2053951717738104. https://doi.org/10.1177/2053951717738104

[101] Taylor Shelton and Thomas Lodato. 2019. Actually existing smart citizens. City 23, 1 (Jan. 2019), 35-52. https://doi.org/10.1080/13604813.2019.1575115

[102] Christo Sims. 2017. Disruptive fixation: School reform and the pitfalls of technoidealism. Vol. 11. Princeton University Press.

[103] Barbara Smith (Ed.). 1983. Home girls: a Black feminist anthology (1st ed ed.). Kitchen Table-Women of Color Press, New York.

[104] Robert Soden, Michael Skirpan, Casey Fiesler, Zahra Ashktorab, Eric P. S. Baumer, Mark Blythe, and Jasmine Jones. 2019. CHI4EVIL: Creative Speculation on the Negative Impacts of HCI Research. In Extended Abstracts of the 2019 CHI Conference on Human Factors in Computing Systems (CHI EA '19). Association for Computing Machinery, New York, NY, USA, 1-8. https://doi.org/10.1145/ 3290607.3299033

[105] Luke Stark and Anna Lauren Hoffmann. 2019. Data Is the New What? Popular Metaphors \&amp; Professional Ethics in Emerging Data Culture. Fournal of Cultural Analytics 1, 1 (May 2019), 11052. https://doi.org/10.22148/16.036

[106] Katy Stegall. 2019. San Diego is fifth-most surveilled city in America, study says. https:/www.sandiegouniontribune.com/news/watchdog/story/2019-0914/san-diego-is-fifth-most-surveilled-city-in-america-study-says

[107] Lucy Suchman. 2002. Located accountabilities in technology production. Scandinavian fournal of Information Systems 14, 2 (Sept. 2002), 91-105.

[108] Maurizio Teli, Marcus Foth, Mariacristina Sciannamblo, Irina Anastasiu, and Peter Lyle. 2020. Tales of Institutioning and Commoning: Participatory Design Processes with a Strategic and Tactical Perspective. In Proceedings of the 16th Participatory Design Conference 2020 - Participation(s) Otherwise - Volume 1 (PDC '20). Association for Computing Machinery, New York, NY, USA, 159-171. https://doi.org/10.1145/3385010.3385020

[109] Austin L. Toombs, Shaowen Bardzell, and Jeffrey Bardzell. 2015. The Proper Care and Feeding of Hackerspaces: Care Ethics and Cultures of Making. In Proceedings of the 33rd Annual ACM Conference on Human Factors in Computing Systems (CHI '15). Association for Computing Machinery, New York, NY, USA, 629-638. https://doi.org/10.1145/2702123.2702522

[110] Vasillis Vlachokyriakos, Clara Crivellaro, Pete Wright, and Patrick Olivier. 2018. Infrastructuring the Solidarity Economy: Unpacking Strategies and Tactics in Designing Social Innovation. In Proceedings of the 2018 CHI Conference on Human Factors in Computing Systems (CHI '18). Association for Computing Machinery, New York, NY, USA, 1-12. https://doi.org/10.1145/3173574.3174055

[111] Jackie Wang. 2018. Carceral Capitalism. MIT Press. Google-Books-ID: O55ODwAAQBAJ

[112] Richmond Y. Wong, Vera Khovanskaya, Sarah E. Fox, Nick Merrill, and Phoebe Sengers. 2020. Infrastructural Speculations: Tactics for Designing and Interrogating Lifeworlds. In Proceedings of the 2020 CHI Conference on Human Factors in Computing Systems (CHI '20). Association for Computing Machinery, New York, NY, USA, 1-15. https://doi.org/10.1145/3313831.3376515

[113] Shoshana Zuboff. 2018. The Age of Surveillance Capitalism: The Fight for a Human Future at the New Frontier of Power (1st ed.)

[114] Sharon Zukin. 2020. The Innovation Complex: Cities, Tech, and the New Economy. Oxford University Press. Google-Books-ID: HjLNDwAAQBAJ.

[115] Sharon Zukin. 2020. Seeing like a city: how tech became urban. Theory and Society 49, 5 (Oct. 2020), 941-964. https://doi.org/10.1007/s11186-020-09410-4 